\title{
SOBRE(VIVER) NO CÁRCERE: GRACILIANO RAMOS E A NUDEZ NA CASA DOS MORTOS
}

\author{
Luciana Araujo Marques ${ }^{1}$
}

Resumo: Este ensaio propõe uma leitura imanente de Memórias do cárcere, de Graciliano Ramos, ao investigar a inscrição, sobretudo, via remissões à corporeidade e ao que a reveste ou a expõe, da tentativa de "morte civil", própria dos procedimentos realizados pelas "instituições totais", formulações de Erwing Goffman em Manicômios, prisões e conventos, assim como a resistência formalizada textualmente pelo autor a propósito do papel social do escritor frente a esse assassínio do eu e do outro, com quem a proximidade máxima e forçada em condições desumanas desafia a sobrevivência em vários sentidos do termo. Manter-se vivo na "casa dos mortos", expressão tomada emprestada da experiência prisional de Dostoiévski, para o título, refere-se não apenas à conservação biológica da vida, mas também ao desafio de um estado de atenção sempre presente em relação ao que não pode se deixar enterrar no passado, como querem os que tentam perpetrar essa morte.

Palavras-chave: morte civil; prisão; memória; resistência.

Abstract: This essay proposes an immanent reading of Graciliano Ramos's Memórias do cárcere [Memories of Prison], examining, mainly via references to corporeality and that which covers it and that which exposes it, attempts to cause a "civil death," characteristic of the procedures conducted by "total institutions," as formulated by Erving Goffman in Asylums: Essays on the social situation of mental patients and others inmates, as well as the author's textually formalized resistance to the social role of the writer faced with this assassination of the self and the other, with whom maximum, forced proximity in inhumane conditions present a challenge to survival in many senses of the word. Staying alive in "the house of the dead," an expression borrowed from Dostoyevsky's prison experience, thus refers not only to the biological preservation of life, but also to the challenge of an ever-present state of attention regarding that which cannot be left buried in the past, as the would-be perpetrators of this attempted death would prefer.

Keywords: civil death; prison; memory; resistance.

1 Doutoranda de Teoria e História Literária do Instituto de Estudos da Linguagem (IEL-Unicamp), integrante dos grupos de Crítica Literária e Psicanálise e Graciliano Ramos: Pontes Literárias, Socioculturais e com Outras Artes (Letras-USP, ambos com certificação CNPq), colunista da Revista Pessoa. E-mail: araujo.lu@gmail.com 


\section{O CORPO É, PORTANTO, O PRÓPRIO, A PRIMEIRA PESSOA. PAUL-LAURENT ASSOUN}

Preso em Maceió sem qualquer acusação ou julgamento formal no dia 3 de março de 1936, Graciliano Ramos (1892-1953) só foi libertado no dia 13 de janeiro do ano seguinte. Nesse período de onze meses de detenção, esteve em três presídios. Primeiro foi embarcado para o Recife, depois levado ao Rio de Janeiro no porão do navio Manaus. Em terras fluminenses, o escritor alagoano ficou encarcerado na Casa de Detenção, no centro da capital, ao lado de outros presos políticos e, mais tarde, transferido para a Colônia Correcional de Dois Rios, na Ilha Grande, junto aos ditos presos comuns. Nessa “ilha funerária”, nas palavras do escritor em Memórias do cárcere (1953), ecoa um grito dirigido aos recém-chegados: "Atenção. Vocês não vêm corrigir-se, estão ouvindo? Não vêm corrigir-se: vêm morrer" (RAMOS, 1996, p. 69, v. II). Imperativo que soa, mesmo quando não dito, nos demais espaços retratados ao longo da narrativa, que compõem e titulam as partes do livro, de modo que "vêm morrer" neste ensaio não respeita uma ordem cronológica de aparição, visto que constante. "Embora não me restasse ilusão, a franqueza nua abalou-me: [...] anunciavam friamente o desígnio de matar-nos. Singular” (RAMOS, 1996, p. 69, v. II; grifo meu).

O narrador em primeira pessoa refere-se à dura "sentença do zarolho" seguidas vezes. Em uma de suas recorrências, a morte anunciada em "vêm morrer" é promessa que se cumpre lentamente: "Em vez de meter-nos em forno crematório, iam destruir-nos pouco a pouco" (RAMOS, 1996, p. 69, v. II), em outra, constata-se com espanto a sua velocidade como imagem refletida no espelho e como anos que se somam em uma idade que Graciliano ainda não tinha: "Era assombroso, porém, aquilo realizar-se tão depressa. A morte se aproximava, surrupiava-me de chofre vinte e dois anos; o resto iria sumir-se evaporar-se" (RAMOS, 1996, p. 73, v. II). A frase lapidar também vem à tona sob máscaras diversas, ainda que, sobretudo, como certeira incógnita: "gemidos, queixas, vozes dúbias, escarros vermelhos, dispneia - livravam-nos dos perigos incertos que em vão queríamos figurar. 'Vêm morrer.' [...] O pior é não saber a gente como vai morrer" (RAMOS, 1996, p. 84, v. II). Berro, portanto, a permanecer como inscrição na corporeidade de quem rememora tantos anos depois o ocorrido, hoje que não passa, mesmo sabendo-se um sobrevivente dono da assinatura ilustre de uma obra (toda a sua), mas também no caso específico desta que, publicada inacabada e póstuma, descumpre a determinação de sepultamento:

Passei o dia remoendo ideias lúgubres. Iam enterrar-me ali. Um pacote leve, alguns ossos envoltos nas duas bandas de lençol tintas de vômito vermelho. Embrulho imundo, anônimo, em cima de uma tábua. Enfim não pretendiam corrigir-nos: queriam apenas matar-nos, dissera o guarda vesgo na primeira noite, procurando esconder o braço pequeno, atrofiado. (RAMOS, 1996, p. 155, v. II)

Se, para Graciliano Ramos, a experiência sempre foi condição de sua escrita (CANDIDO, 2006, p. 82), até para suas ficções, isso não significa precisão no registro do vivido, mesmo no caso de suas memórias, de inegável teor testemunhal. Seja em Infância (1945) ) seja nas Memórias, em que o eu que narra coincide com o nome que assina a autoria na capa, 
estabelecendo o pacto autobiográfico, o autor sempre chama a atenção para o esburacamento operado pelo esquecimento, para a consequente impossibilidade de reconstrução total dos fatos, assim como para o entroncamento entre o rememorado e a imaginação, próprio do gênero memória.

Chama atenção, por exemplo, a descrição detalhada feita por Graciliano do "bichinho aleijado e branco, de farda branca e gorro certinho, redondo. Parecia ter uma banda morta" (RAMOS, 1996, p. 69, v. II), aquele que diz "vêm morrer", portador da "franqueza nua", que o abalara, não sem deixar de fazer a ressalva quanto à fidedignidade do lembrado: "Era vesgo e tinha um braço menor que o outro. Suponho". "Impressão momentânea" que se perpetua no literário: "Não me seria possível afirmar, foi impressão momentânea. Um sujeito miúdo, estrábico e manco a compensar todas as deficiências com uma arenga enérgica” (RAMOS, 1996, p. 69, v. II). Não importa a precisão quanto às características do dizente fúnebre, se de fato um de seus braços era mais curto ou não, tampouco o julgamento moral de uma pessoa salientado por um problema físico, o que hoje em dia, inclusive, seria julgado como politicamente incorreto, mas justamente a imagem que se pretende construir daquelas ruínas e do sujeito ali. Ao relacionar a indumentária daquele que exclama o assassinato de todos às suas deficiências pela aproximação textual entre o corpo e as insígnias do tecido que o recobre de poder, o escritor ressalta a impotência e o aleijamento de todo um corpo que encarna o caráter da instituição que fala por meio dele, de todo um país que fala por meio desta instituição. Ainda que Graciliano não deixe de realizar uma absolvição irônica, na toada de seu aprendizado da antinomia, outro tópico relevante das Memórias: "Certamente era absurdo responsabilizar o Brasil, quarenta milhões de habitantes, pela sentença do zarolho. Ali dentro haveria criaturas bem-intencionadas, mas não nos valeriam muito na engrenagem que nos agarrava" (RAMOS, 1996, p. 69, v. II). O corpo deficiente em questão trata-se daquele próprio das sociedades sob fardas, isto é, corpo orgânico, no qual cada um tem um lugar "natural" sob "cabeça" única, no caso o ditador, uma concepção típica dos totalitarismos.

Em contraste com os uniformes e gorros que assinalam a hierarquia dentro do espaço prisional, Graciliano mostra-se o tempo todo atento à nudez (literal e não apenas) a que são submetidos todos aqueles que "vêm morrer". A "franqueza nua" daquele que sela o destino de vidas matáveis, que "desmanchar-se-iam anônimos em covas abertas" (RAMOS, 1996, p. 310, v. II), é revestida da autoridade a ser combatida. A nudez, nesse caso, não está ligada à liberdade de roupas impostas ou apenas ao que poderia soar inconveniente a um nordestino acostumado a ser visto em público apenas engravatado, mesmo sob o forte calor de Alagoas ou do Rio de Janeiro da década de 1930, como Graciliano, ${ }^{2}$ mas justamente à privação daquilo que é construído socialmente a revestir os seres e suas posses, à perda submetida pela prisão pela imposição de uma "morte civil", via "profanações do eu" e padronizações nas "instituições totais", nos termos de Erving Goffman em Manicômios, prisões e conventos. Entre essas rupturas está a que se dá com a própria imagem de si, que será mutilada, "codificad[a] num objeto que pode ser colocado na máquina administrativa” (GOFFMAN, 2007, p. 26), com suas regras, operações de rotina, padronizações: digitais são colhidas; fotografias

2 Ainda que esse pudor seja um assunto conveniente a ser analisado. São muitos os episódios nas Memórias que abordam a nudez de forma direta e que renderiam uma leitura mais detida sobre suas implicações e diferenciações para além do sentido de "morte civil" aqui tratada, e que pretendo desenvolver em outros textos. 
tiradas; números atribuídos no lugar dos nomes; cabeças são raspadas; bens pessoais são confiscados; o contato com os que estão fora é restrito. Há o despojamento violento dos papéis anteriores nos quais os internos se reconheciam no mundo externo, além do exercício de funções com as quais não se identificam. Na versão cinematográfica de Nelson Pereira dos Santos das Memórias (1984), por exemplo, os presos são colocados para cavar buracos, atividade que, sob o refrão de "vêm morrer", pode ser associado a dos coveiros (de si).

A imagem da "engrenagem que nos agarrava", nas palavras de Graciliano, que, tal Josef K., é detido "sem ter feito mal algum" (KAFKA, 2006 p. 7), apesar de se julgar "autor de várias culpas", "não sabia determiná-las", "nem uma vez me viera a ideia de estar sendo vítima de injustiça” (RAMOS, 1996, p. 56 e p. 151, v. I), ilustra esse funcionamento maquinal, que foi tão bem construído por Kafka em outra obra, a novela $\mathrm{Na}$ colônia penal, uma vez que o aparelho, desenvolvido pelo comandante responsável pela instalação de todo o complexo de castigos, escreve na carne do condenado o mandamento infringido - um exemplo de inscrição: Honra teu superior! (KAFKA, 1998, p. 36; grifo no original). Nessa máquina: "O condenado é posto de bruços sobre o algodão, naturalmente nu" (KAFKA, 1998, p. 33; grifo meu).

A consciência dessa nudez imposta tem até certo ponto um paralelo com o mito bíblico, que tem como protagonistas Adão e Eva, como representantes de toda a humanidade - "Eles perceberam que estavam nus" (Gênesis, 3,7) - uma vez que, na cultura ocidental cristã, a nudez carrega uma herança teológica pesada. Se em termos dessa teologia, a graça sobrenatural que circundava o humano é perdida com o pecado, esse corpo sem glória, o nu da pura corporeidade, é exposto em sua pura funcionalidade biológica, em sua sexualidade, mas também em sua corrupção e putrefação, como assinala Giorgio Agamben (2014) em "Nudez".

Em Memórias do cárcere, grande parte desses procedimentos desumanizadores é assunto de uma empreitada que dá feições ao desfiguramento empreendido. Poderia se arriscar aqui a hipótese de que enquanto a maioria sofre a perda da imagem usual de si, o escritor, por certa persistência, parece reforçar seu papel de testemunha no território além-muros (além-mar, no caso da ilha), além-morte, próprio do literário, o que não significa que as mortificações não ocorram. Ao contrário, a morte faz dele (escritor) morada e como ele próprio torna-se assunto de seu trabalho, é a partir dela que fala como sobrevivente. ${ }^{3}$ Sobreviver e morrer sobrepõem-se tantas vezes.

O seu ajuste à situação é eloquente: fecha o corpo, não ingerindo alimento, nem o eliminando, numa crispação negativa; e, no meio do pandemônio e da abjeção, redige sem parar notas em que descreve, pesa a situação; embora perdidas depois, elas formarão o núcleo germinal das Memórias do cárcere. Resiste, pois, tenazmente ao meio, nega-se às suas leis e encontra equilíbrio, precário, mas decisivo, nas pequenas folhas de papel em que afirma a sua autonomia espiritual. A literatura é o seu protesto, o modo de manifestar a reação contra o mundo das normas constritoras (CANDIDO, 2006, p. 89; grifos meus).

3 Graciliano não é o único escritor na prisão. Outros tentam a mesma tarefa árdua. A certa altura, inclusive, o alagoano se refere com certa preguiça e nenhum romantismo ao fato de que: "Naquele tempo grassava na cadeia uma epidemia literária" (RAMOS, 1996, p. 218, v. II). 
Resistir, no caso de um jejum como o de Graciliano Ramos, para além do fechamento do corpo ao alimento nauseabundo nos termos simbólicos destacados por Candido, implica concretamente a falta de nutrientes e a garantia de energia para estar seguir vivo. Seu prolongamento acarreta doença física que pode arruinar, inclusive, a "fuga da situação por meio da criação mental", "seu jeito peculiar de inserir-se nele, de nele definir um lugar", como $\neg \neg \neg \neg$ atesta Candido na sequência do trecho citado acima. A repugnância que lhe causava a comida, provisão de vida, não é da ordem de um protesto calculado, performático ou heroico-literário, mas corporal em alta intensidade, o que não se pode perder de vista. Paradoxalmente, o jejum era uma rejeição à morte, mas que também matava pouco a pouco.

Não é por falta de opções na língua portuguesa que as "marmitas" dos presos são transportadas em "caixões" na narrativa de Graciliano, aproximando-as, como recipientes de alimento, do léxico da morte, e das trevas, em plena luz do meio-dia. O envenenamento, como se destaca a seguir, é efetivo de uma forma ou de outra. Não há fechamento de corpo que o impeça:

Por volta de meio-dia trouxeram-nos caixões com marmitas e o almoço foi distribuído. Olhei de longe a comida feia, mas não foi o aspecto desagradável que me fez evitá-la: reaparecera-me a inapetência, e só a vista do alimento me provocava náuseas. [...] Espantava-me conseguir uma pessoa mastigar qualquer coisa diante das imundícies que se agitavam e descompunham na vaga de mijo. O fedor horrível, confusão de cheiros com predominância de amoníaco, já não me afligia: habituara-me a ele e envenenava-me sem perceber isto. (RAMOS, 1996, p. 150, v. I)

Lembremos ainda do café que era servido na Casa de Detenção e que lhe extinguia o desejo sexual (e o que esta impotência refletia em seu não mais se sentir um homem). Justamente a bebida, além do cigarro, que Graciliano consumia em abundância - se é possível falar em "abundância" na cadeia:

Eu abusava do café. Certa manhã, fornecendo-me o segundo caneco, o faxina me proporcionou este aviso:

__ Se o senhor soubesse o que há nisto, não bebia tanto.

Indaguei, o tipo encolheu os ombros e ficou por aí. Desatento ao conselho, não me abstive do líquido enjoativo, adocicado. E nem de longe suspeitei que o gostinho de formiga tivesse ligação com o prolongado esmorecimento. (RAMOS, 1996, p. 232, v. I)

A solidariedade existente entre os companheiros de prisão não estimula o "corpo fechado" enaltecido pela crítica como sinal de resistência, afinal, é preciso insistir para que Graciliano se alimente, mesmo que em vão: "Convidaram-me com insistência, quiseram levar-me para junto dos caixões e das marmitas. Algumas pessoas estranharam a recusa. Um dia inteiro em jejum" (RAMOS, 1996, p. 151, v. I). Quem está preocupado com a ma- 
nutenção de vidas que "vêm morrer"? O escritor resiste com uma estranha tranquilidade (aquela de quem está impedido de ação, aquela a quem lhe faltam forças?). Mesmo faminto, o corpo todo latejando precariedade, persevera um senso de propriedade diante do que lhe querem tomar:

Ligeiras picadas no estômago faziam-me pensar nos caixões e nas marmitas, enojado. Nenhuma fome: com certeza não me seria possível engolir nada. As goelas queimavam, os beiços rachados ardiam, e achava-me tranquilo. Realmente não era tranquilidade perfeita. Inclinando-me um pouco, via lá embaixo, numa ponta do estrado, a valise, a calça, o paletó, o chapéu; de quando em quando me voltava para vigiar estes bens. Algumas cédulas, níqueis e pratas estavam em segurança, no porta-moedas, escondido no bolso do pijama, por baixo do lenço. (RAMOS, 1996, p. 153, v. I)

O episódio tantas vezes citado, em que Graciliano se afirma como um proprietário, em resposta a um companheiro de prisão que o acusa de agir como um pequeno burguês, por tomar posse de uma cama sem consultar o coletivo, reforça essa resistência ao reforço da ausência de bens típico das instituições totais, ainda que no contexto em questão, o gesto possa ter sido interpretado como contraditório em relação a posição política do alagoano. É bom lembrar que Graciliano filia-se ao Partido Comunista Brasileiro apenas quando é posto em liberdade, mas já era autor de São Bernardo (1934) cujo enredo da ascensão de Paulo Honório se aproxima de um comentário a partir da convivência travada com um estivador nas Memórias. Observação feita enquanto homem das brenhas: "o enxadeiro largava o eito, arranjava empréstimo, economizava indecente, curtia fome, embrenhava-se em furtos legais, chegava a proprietário e adquiria o pensamento e os modos do explorador" (RAMOS, p. 252, v. I). Já a partir desse ponto o desenrolar descamba mais para o destino dos cangaceiros, ${ }^{4}$ mas também para a sina de tantos outros presos de outras regiões do país, não apenas o sertão, e que Graciliano conhece de perto em seu encarceramento: "a miserável trouxa humana, batida a facão e a vergalho de boi, resistente ao governo, à seca, ao vilipêndio, resolvia tomar vergonha, amarrar a cartucheira à cinta, sair roubando, incendiando, matando como besta-fera" (RAMOS, 1996, p. 252, v. I).

A mortificação, em seu estágio mais elevado, se dá de modo que seja completada pela automortificação, afirma Goffman (2007, p. 48). Nesse sentido, ressalto a análise que faz Fabio Cesar Alves na seção intitulada "O carrasco de si mesmo", de seu livro Armas de papel: Graciliano Ramos, as Memórias do cárcere e o Partido Comunista Brasileiro. O crítico destaca a "análise impiedosa de si mesmo" e a "autoinspeção exercitada pela consciência", bastante típicas de Graciliano, sobretudo, ao tratar de sua obra, só que no contexto específico da prisão, de modo que ele o faz com relação a sua posição político-partidária, em "figuração íntima", na qual a ruína física é também moral. Impiedade e inspeção, a propósito, são eleições vocabulares bastante exemplares desse processo de mortificação civil, da perda

4 Cf. RAMOS, Graciliano. Cangaços (2014). Sobre a temática do cangaço e sua relação com Vidas secas e Deus e o Diabo na terra do Sol, de Glauber Rocha, escrevi “Graciliano e os Lampiões: quando escurece na terra do sol” (MARQUES, 2016, pp. 181-202). 
do papel social (provedor viril, no caso de Graciliano), ainda que Alves não se utilize desta mesma nomenclatura nem cite Goffman em sua bibliografia. Vejamos este trecho sobre a primeira visita que Heloísa, mulher de Graciliano, faz a ele na cadeia:

A figura do chefe do lar atormentado pela inoperância imposta e, também, a imagem do pequeno proprietário que detém a tradição do provento e do mando são sintetizadas pela frase "nada me seria possível dar-lhe [a Heloísa]". A formulação, de corte mais genérico, alude, além das provisões financeiras, à vida conjugal (sexual) igualmente bloqueada, ao homem arruinado que não tem mais condições físicas de "satisfazer" a esposa [...]. Não há como deixar de perceber as reações brutais e de certa forma autoritárias que o narrador atribui a si enquanto prisioneiro, quando este vê interrompido o exercício do poder doméstico ao constatar que a cadeia põe em xeque a sua imagem e as suas funções sociais antes exercidas. (ALVES, 2016, p. 127; grifos meus)

Mais adiante, Fabio Cesar Alves observa que "a cadeia, ao desfacializá-lo, retira-lhe a própria masculinidade. Ao mesmo tempo, tal destituição põe em questão o seu olhar sobre a mulher [a dele, mas as outras com quem convive]" (ALVES, 2016, p. 129; grifo meu). E, mais uma vez, a partir da dura reflexão esmiuçada em seus escritos, Graciliano, por meio daquilo que lhe mortifica, debate-se em um "enfrentamento contra si próprio, contra as suas prerrogativas de classe e de gênero” (ALVES, 2016, p. 129).

Sobreviver à mortificação, à perda da veste, por assim dizer, manter-se vivo, não se dá, portanto, por mera escolha, mas por uma insistência que dura os anos todos de sua escrita e da latência desta escrita. A morte espreita Graciliano tanto quanto os outros, submetidos ao mesmo processo. Não à toa o "vêm morrer" é plural, mas simultaneamente "singular" a sentença. O escritor se impõe um dever ético próprio de seu ofício, de manter vivos os que foram condenados a essa morte, de resistir à aniquilação como exercício "penoso", nos dois sentidos do termo, apesar da impossibilidade de sua conclusão. (Paira uma consciência de que já poderia estar morto quando publicadas as Memórias.) Assim como uma totalização em relação ao passado também não convém, visto que a temporalidade imperiosa é a do próprio presente nessas Memórias, e sua nudez escancarada. 


\section{REFERÊNCIAS}

AGAMBEN, Giorgio. Nudez. Trad. Davi Pessoa. Belo Horizonte: Autêntica, 2014.

ALVES, Fabio Cesar. Armas de papel: Graciliano Ramos, as Memórias do cárcere e o Partido Comunista Brasileiro. São Paulo: Editora 34, 2016.

AUSSOUN, Paul-Laurent. Le corps: L’Autre métapsychologie. In: Introduction à la métapsychologie freudiene. Paris: PUF, 1993.

BASTOS, Hermenegildo. Memórias do cárcere: literatura e testemunho. Brasília: UNB, 1998.

CANDIDO, Antonio. Ficção e confissão. Rio de Janeiro: Ouro sobre Azul, 2006.

FERNANDES, Maria Helena. Corpo. São Paulo: Casa do Psicólogo, 2011.

GOFFMAN, Erving. Manicômios, prisões e conventos. Trad. Dante Moreira Leite. São Paulo: Perspectiva, 2007.

KAFKA, Franz. O veredicto/ Na colônia penal. Trad. Modesto Carone. São Paulo: Companhia das Letras, 1998.

. O processo. Trad. Modesto Carone. São Paulo: Companhia das Letras, 2006.

MARQUES, Luciana Araujo. Graciliano e os Lampiões: quando escurece na terra do sol. In: PEREIRA, Marcos Paulo T. \& LACHAT, Marcelo (orgs.), Pelo sertão, o Brasil. Macapá: Unifap, 2016.

RAMOS, Graciliano. Memórias do cárcere [1953], dois vol., 32a ed. Rio de Janeiro: Record, 1996. . Cangaços. LEBENSZTAYN, Ieda \& SALLA, Thiago Mio (orgs.). Rio de Janeiro: Record, 2014. 